Original Article

Artigo Original

Mariana San Jorge de Castro ${ }^{1}$ Adyléia Aparecida Dalbo Contrera Toro ${ }^{2}$

Eulália Sakano ${ }^{3}$ José Dirceu Ribeiro²

Keywords

Stomatognathic system Asthma

Mastication

Deglutition

Articulation disorders

Child

Descritores

Sistema estomatognático

Asma

Mastigação

Deglutição

Transtornos da articulação

Criança

Correspondence address:

Mariana San Jorge de Castro

R. Álvaro Muller, 560/51, Guanabara,

Campinas (SP), Brasil, CEP: 13023-180.

E-mail: marianafono@yahoo.com

Received: 4/16/2011

Accepted: 9/22/2011

\section{Evaluation of oral functions of the stomatognathic system according to the levels of asthma severity}

\author{
Avaliação das funções orofaciais do sistema \\ estomatognático nos níveis de gravidade de asma
}

\begin{abstract}
Purpose: To compare the orofacial functions (chewing, swallowing and speech) in children with asthma and healthy children. Methods: A cross sectional study including 54 children of both genders with ages between 7 and 10 years was conducted. Twenty-seven of these subjects composed the experimental group, and were subdivided into two severity levels of asthma: Group I - mild intermittent and persistent asthma; Group II persistent moderate to severe asthma. Twenty-seven healthy children were included in the control group (Group III). Speech-language pathology evaluation used the adapted Orofacial Myofunctional Assessment Protocol. Adaptation consisted in the exclusion of the structural part of the test, since this was not the aim of the study. The structural part was excluded because it was not the aim of this study. Results: It was found alterations in oral functions, with significant differences between the three groups. These alterations showed no correlation with asthma severity, since the highest rate of alterations was found in Group I (mild asthma). Conclusion: Regardless of the severity level, children with asthma have altered patterns of chewing, swallowing and speech.
\end{abstract}

\section{RESUMO}

Objetivo: Avaliar as funções orofaciais de mastigação, deglutição e fala em crianças asmáticas e crianças saudáveis. Métodos: Estudo de corte transversal com 54 crianças, com idades entre 7 e 10 anos completos, de ambos os gêneros. Do total, 27 compuseram o grupo experimental e foram subdivididas em dois níveis de gravidade de asma: Grupo I - asma intermitente ou persistente leve; Grupo II - asma persistente moderada ou grave. Fizeram parte do grupo controle (Grupo III) 27 crianças saudáveis. Para a avaliação fonoaudiológica foi utilizado o Protocolo de Avaliação Miofuncional Orofacial adaptado. A adaptação constituiu na exclusão da parte estrutural, já que esta não fazia parte do objetivo do estudo. Resultados: Alterações nas funções orofaciais foram encontradas, com diferenças entre os três grupos estudados. Essas alterações não tiveram relação com a gravidade da asma, visto que o maior índice de alterações foi encontrado no Grupo I (asma leve). Conclusão: Independentemente do nível de gravidade da doença, crianças asmáticas apresentam padrões alterados de mastigação, deglutição e fala.
Study conducted at the School of Medical Sciences, Universidade Estadual de Campinas - UNICAMP Campinas (SP), Brazil.

(1) Graduate Program (Masters degree) in Child and Adolescent Health, School of Medical Sciences, Universidade Estadual de Campinas - UNICAMP - Campinas (SP), Brazil.

(2) Department of Pediatrics, Universidade Estadual de Campinas - UNICAMP - Campinas (SP), Brazil. (3) Department of Otorhinolaryngology, Universidade Estadual de Campinas - UNICAMP - Campinas (SP), Brazil.

Conflict of interests: None 


\section{INTRODUCTION}

The Stomatognathic System (SS) is composed of bones, muscles, joints, teeth, lips, tongue, cheeks, glands, arteries, veins, and nerves, which perform the functions of sucking, chewing, swallowing, speech and breathing. Such structures are not individually specialized in a particular function, i.e., they act together, so that any specific anatomic or functional modification can lead to imbalances and several types of alterations ${ }^{(1,2)}$

According to the guidelines of Allergic Rhinitis and Its Impact on Asthma (ARIA) ${ }^{(3)}$, nasal and bronchial mucosa have many similarities. Through studies in several countries, the Project ARIA has consistently shown that asthma and rhinitis often coexist within the same patient. There are indications that the upper and lower airways are affected by a common inflammatory process that can be maintained and amplified by interconnected mechanisms.

Asthma can be classified as intermittent, mild persistent, moderate persistent or severe persistent. It is estimated that $60 \%$ of cases are intermittent or mild persistent, moderate are $25-30 \%$, and $5-10 \%$ of them are severe ${ }^{(4)}$.

To achieve and justify the relationship between the SS tasks and asthma through the concept of unified airway, some studies have emphasized the relationship between the SS and allergic rhinitis (AR). The triad of sneezing, nasal obstruction and itching are the most common components of $\mathrm{AR}^{(5,6)}$. The consequences of nasal obstruction on orofacial structures have also been measured ${ }^{(7-9)}$. However, there are few studies that relate directly the $\mathrm{SS}$ and $\mathrm{AR}^{(10)}$

The AR alters the functions of breathing, chewing and swallowing, and the higher nasal obstruction, the greater the functional changes in the $\mathrm{SS}^{(11)}$. The structural and functional alterations of the SS in asthma, even considering the concept of oneness of the airways, are little explored.

Studies have described the characteristics of the processes of chewing and swallowing in patients with nasal obstruction due to AR and asthma ${ }^{(12,13)}$. Parents reported that due to difficulty breathing, children have fatigue in chewing and insufficient food intake ${ }^{(12)}$

One study ${ }^{(13)}$ characterized the patterns of facial anthropometry, identified the presence of facial asymmetry and related the prevalence of masticatory side with the presence of facial asymmetry in children with and without asthma. The authors selected 60 children between 6 and 10 years of age. Of these, 30 had moderate or severe persistent asthma and 30 had no asthma. Anthropometric facial and chewing variables were measured. The authors found no differences in measurements between the groups. Regarding the presence of facial asymmetry, it was observed that they occurred in both groups. The predominant chewing pattern in both groups was simultaneous bilateral, and when the facial asymmetry and masticatory pattern were related there were no significant associations.

Studying swallowing, some authors ${ }^{(14)}$ emphasized the prevalence of involvement of the perioral muscles, with anterior projection of the tongue and head, noisy swallowing, interposition of lower lip and significant changes in resting posture of lips in allergic rhinitis and asthma.
In order to delineate the prevalence, severity and symptoms associated with asthma, studies were conducted with children and adolescents in some Brazilian cities ${ }^{(15-17)}$. In these, among other findings, it was highlighted the presence of speech disorders in children with asthma. This change has been poorly characterized. The authors reported that the speech was limiting the presence of wheezing, a finding confirmed by a statistically significant difference.

Given the above, the present study was to evaluate the oral functions of mastication, swallowing and speech in children with asthma and healthy children.

\section{METHODS}

This is a cross-sectional study. Participants were children of both genders aged between 7 and 10 years, patients of the Division of Pediatric Pulmonology Clinic of Pediatrics, Hospital de Clínicas da Universidade Estadual de Campinas (HC/UNICAMP), from June/2009 to June/2010.

To compose the experimental groups 27 children diagnosed with asthma were selected, who were subdivided according to severity levels proposed by the Allergic Rhinitis and Its Impact in Asthma (ARIA) ${ }^{(3)}$ : Group I - intermittent or mild persistent asthma, and Group II - moderate persistent asthma or severe persistent.

The diagnosis of AR was performed as recommended by the ARIA $^{(3)}$, intermittent or persistent according to duration and as mild or moderate-severe with respect to intensity. Depending on the predominant symptoms, patients with AR were divided into mild intermittent, moderate-severe intermittent, mild persistent, moderate persistent or severe.

We excluded subjects who had at least one of the following criteria: no consent of the child, parent or guardian to participate in the research, children physically or mentally disabled and/ or patients with neurological disease, who underwent speech therapy, with changes craniofacial morphology and occlusal; those exposed to orthodontic or otorhinolaryngology surgery, who had a history of oral habits such as thumb sucking, pacifier use, bottle and nail biting, over the age of three years, with concomitant AR framework, which intermittent character possessed moderate-severe and persistent, according to the classification of ARIA. The presence of any of these items could exert influence on the structural and functional patterns of the stomatognathic system, not allowing, therefore, reliable results for the characterization of this population.

After the diagnosis of asthma without AR or asthma with mild intermittent AR level, parents or guardians were asked about the inclusion and exclusion criteria. If there was positive response to any of the exclusion criteria, patients were automatically removed from the study.

The control group (Group III) consisted of 27 healthy individuals of both genders, also aged between 7 and 10 years, students enrolled at a state school. There was no difference in gender distribution for the studied groups. For the selection of children from Group III, the parents or guardians completed a brief questionnaire, containing exclusion criteria adopted for this study. The positive response to any of the criteria described 
above excluded the child from the research. Then, for the classification of AR according to the criteria mentioned by ARIA, parents were asked about the duration and symptoms of normal sleep, daily activities, sports and recreation activities at school and uncomfortable symptoms. After the selection of children from group III, the parents consented performing the evaluation, what happened at the school, through the Statement of Informed Consent (SIC).

We evaluated the functional aspects exercised directly (chewing, swallowing, and speech) and indirectly (respiration) by the stomatognathic system.

\section{Adapted Orofacial Myofunctional Assessment Protocol}

For the clinical assessment of oral functions of mastication, swallowing, speech, and the breathing mode the adapted Orofacial Myofunctional Assessment Protocol ${ }^{(18)}$ was used. The adaptation consisted in the exclusion of the structural part, since this was not part of the study's objective.

\section{Mastication}

For evaluation of mastication the children were offered cheese bread, food of solid consistency. The masticatory function was evaluated by type, mode, and speed. The researcher who conducted the assessment for all children in the experimental groups was previously trained to perform the same procedures in healthy children.

We considered the masticatory type in relation to the position of grinding the food in the dental arches, with the following classification:

- Adequate (bilateral alternate): when chewing was performed on both sides of the dental arches alternately. It is the expected standard and chewing.

- Inadequate (unilateral): when chewing was performed only on one side of the dental arches.

To determine the side on which chewing occurred, the researcher positioned the hand in the area of the masseter and watched the side where the food was being crushed ${ }^{(19)}$. To confirm this finding, it was requested that in some moments, during the grinding process, the child opened her mouth, so that the researcher visualize the position in which it was being crushed.

Chewing mode was classified according to the position of the lips during mastication, considering:

- Adequate (with labial closure): when the lips remained sealed during mastication.

- Inadequate (without labial closure): when the lips are not kept sealed during mastication.

The mastication speed was classified as normal, increased or decreased. To evaluate the chewing rate a timer was used, measuring the time chewing the cheese bread. Then, the average was taken of the time spent, with the standard of normality having the average time of 10 seconds chewing 0.05 grams of food (cheese bread) before the swallowing ${ }^{(19)}$

The chewing rate was classified as follows:

- Adequate: when the time to complete chewing was equal to the average obtained in the previous study ${ }^{(19)}$.
- Increased, when the time to complete chewing was higher than the average obtained in the previous study ${ }^{(19)}$.

- Reduced: when the time to complete chewing was lower than the average obtained in the previous study ${ }^{(19)}$.

\section{Swallowing}

For the evaluation of swallowing, water at room temperature and cheese bread were used. We evaluated possible occurrences: anterior projection of the tongue, moving his head back in order to facilitate the oral transit of food, stasis in the oral cavity after swallowing; exaggerated periorbicular contraction of the muscles of the lips, aiming at compensating the hypotonicity of other muscular chains; exaggerated contraction of the mentalis muscle in order to compensate for the hypotonicity of the lower lip; interposition of the lower lip.

From these parameters, swallowing was considered ${ }^{(19)}$ :

- Adequate: when patients do not present any of the above characteristics.

- Inadequate: when the patients had one or more of the above characteristics.

\section{Speech}

For the evaluation of speech there were made tests of spontaneous speech, naming of phonetically balanced pictures, and count from 1 to $20^{(18)}$. In these tests it was observed the presence or absence of articulatory inaccuracies, distortions, omissions and substitutions ${ }^{(20)}$. It is worth mentioning that it was considered as articulatory imprecision the laborious speech, such as distortion and the presence of anterior or lateral lisp.

The parameters used to classify speech as adequate or were altered:

- Adequate: when the patient had no omissions, substitutions, distortions and/or inaccuracies of speech sounds.

- Inadequate: when were observed any of the above changes.

\section{Ethical aspects}

The groups were composed of individuals considered vulnerable because they have no maturity and knowledge to discern any risks inherent to the study. Children were included only after signing the Statement of Informed Consent (SIC) by the responsible. Thus, the participation was consensual and dissemination of research and its results is in accordance with Resolution 196/96 (BRASIL. Resolution MS/CNS/CNEP n ${ }^{\circ}$ 196/96 of October 10,1996). This study was approved by the Ethics Committee of the Faculty of Medical Sciences, State University of Campinas (FCM/UNICAMP), under number $575 / 2004$.

\section{Statistical analysis}

To describe the sample profile according to the variables under study there were made frequency tables of categorical variables, with values of absolute frequency (n), percentage $(\%)$, and descriptive statistics of numeric variables, with mean 
values, standard deviation, minimum, maximum and median.

To compare categorical variables between groups we used the chi-square or Fisher exact test (for expected values less than $5)$. To compare numerical variables between the three groups we used the Kruskal-Wallis test due to absence of normal distribution of variables. The level of significance for statistical tests was $5 \%$ or 0.05 .

\section{RESULTS}

We evaluated the stomatognathic system regarding oral functions of mastication, swallowing and speech.

In evaluating the masticatory process, differences were found between the three groups in the position in which it was crushed in the dental arches and the speed of the masticatory process (Table 1).

The variables that define the quality of swallowing of the cheese bread were analyzed. In the categories "anterior projection of the tongue", "food stasis in the oral cavity", "periorbicular muscle contraction" and "contraction of the mentalis muscle," there was no difference between the groups. The variables "moving head" and "bringing the lower lip" showed no difference (Table 2).

In swallowing water, we analyzed the variables "previous projection of tongue," "moving head", "periorbicular muscle contraction", "contraction of the mentalis muscle", "interposition of the lower lip". There were differences in all variables, subject to the variable "head movement", which showed a homogeneous sample among the three groups, i.e., presented no difference between them (Table 3 ).

To analyze the speech quality of the participants, we verified the presence of omissions, substitutions, distortions, and inaccuracies during spontaneous speech, naming and repetition of given words. The variable "distortions" stood out as prevalent in Group I. No differences were found in relation to other variables (Table 4).

\section{DISCUSSION}

The direct consequences of asthma in the structures and functions of the stomatognathic system are still poorly explored and studied ${ }^{(10)}$. Few empirical studies were found with regard to this relationship.

\section{Chewing versus asthma}

Analyzing the results of the evaluation, it was observed that the variables "position in which it was crushed in the dental arches", "labial seal", and "speed" that characterize mastication as appropriate or as amended, were considered. The results

Table 1. Comparative analysis of variables related to chewing

\begin{tabular}{|c|c|c|c|c|}
\hline \multirow[b]{2}{*}{ Chewing variables } & \multicolumn{3}{|c|}{ Groups } & \multirow[b]{2}{*}{$\mathrm{p}$-value } \\
\hline & $\begin{array}{c}\text { Group I } \\
\mathrm{n}=14 \\
(\%)\end{array}$ & $\begin{array}{c}\text { Group II } \\
n=13 \\
(\%)\end{array}$ & $\begin{array}{c}\text { Group III } \\
\text { n= } 27 \\
(\%)\end{array}$ & \\
\hline Position of food - alternate bilateral & $5(35.71)$ & $5(38.46)$ & 25 (92.59) & $<0.001^{*}$ \\
\hline Position of food - unilateral & $9(64.29)$ & $8(61.54)$ & $2(7.41)$ & $<0.001^{*}$ \\
\hline Increased speed & $3(21.43)$ & $5(38.46)$ & $1(3.70)$ & $0.011^{*}$ \\
\hline Decreased speed & $3(21.43)$ & $2(15.38)$ & $0(0.00)$ & $0.040^{*}$ \\
\hline
\end{tabular}

* Significant values $(\mathrm{p} \leq 0.05)$ - Fisher's exact test

Note: Group I = mild intermittent or mild asthma; Group II = moderate or severe persistent asthma; Group III = healthy children

Table 2. Comparative analysis of variables related to swallowing solid food

\begin{tabular}{|c|c|c|c|c|}
\hline \multirow[b]{2}{*}{$\begin{array}{l}\text { Swallowing variables } \\
\text { (1 } 1^{\text {st }} \text { test) }\end{array}$} & \multicolumn{3}{|c|}{ Groups } & \multirow[b]{2}{*}{$p$-value } \\
\hline & $\begin{array}{c}\text { Group I } \\
\mathrm{n}=14 \\
(\%)\end{array}$ & $\begin{array}{l}\text { Group II } \\
\text { n=13 } \\
(\%)\end{array}$ & $\begin{array}{c}\text { Group III } \\
\mathrm{n}=27 \\
(\%)\end{array}$ & \\
\hline Anterior projection of the tongue & $14(100.0)$ & $11(84.62)$ & $5(18.52)$ & $<0.001^{* *}$ \\
\hline Atypical movement of the head & $0(00.0)$ & $0(00.0)$ & $0(00.00)$ & 1.000 \\
\hline Food stasis in the oral cavity & $10(71.43)$ & $6(46.15)$ & $2(7.41)$ & $<0.001^{*}$ \\
\hline Contraction of periorbicular muscle & $9(64.29)$ & $8(61.54)$ & $3(11.11)$ & $<0.001^{* *}$ \\
\hline Contraction of the mentalis muscle & $14(100.0)$ & $13(100.0)$ & $2(7.41)$ & $<0.001^{* *}$ \\
\hline Interposition of the lower lip & $5(35.71)$ & $4(30.77)$ & $2(7.41)$ & $0.051^{*}$ \\
\hline
\end{tabular}

* Significant values $(p \leq 0.05)-$ Fisher's exact test

** Significant values $(\mathrm{p} \leq 0.05)-$ Chi-square test

Note: Group I = mild intermittent or mild asthma; Group II = moderate or severe persistent asthma; Group III = healthy children 
Table 3. Comparative analysis of variables related to swallowing liquids

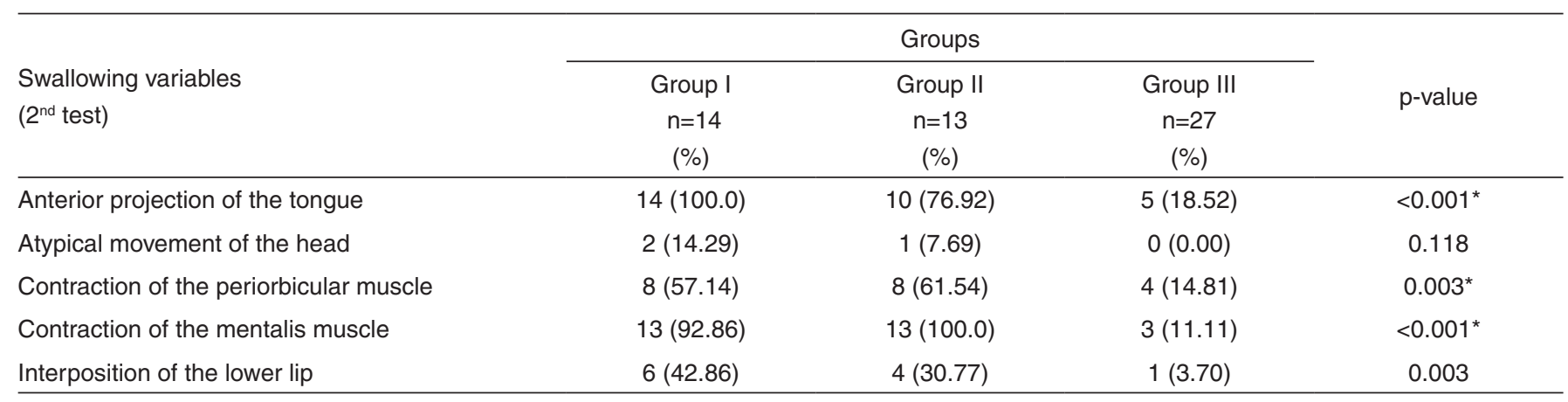

* Significant values $(p \leq 0.05)$ - Fisher's exact test

Note: Group I = mild intermittent or mild asthma; Group II = moderate or severe persistent asthma; Group III = healthy children

Table 4. Comparative analysis of variables related to speech

\begin{tabular}{|c|c|c|c|c|}
\hline \multirow[b]{2}{*}{ Speech } & \multicolumn{3}{|c|}{ Groups } & \multirow[b]{2}{*}{$p$-value } \\
\hline & $\begin{array}{c}\text { Group I } \\
\mathrm{n}=14 \\
(\%)\end{array}$ & $\begin{array}{c}\text { Group II } \\
\text { n=13 } \\
(\%)\end{array}$ & $\begin{array}{c}\text { Group III } \\
\begin{array}{c}n=27 \\
(\%)\end{array}\end{array}$ & \\
\hline Omissions & $1(7.14)$ & $1(7.69)$ & $0(0.00)$ & 0.245 \\
\hline Substitutions & $2(14.29)$ & $0(0.00)$ & $0(0.00)$ & 0.118 \\
\hline Distortions & $10(71.43)$ & $5(38.46)$ & $3(11.11)$ & $<0.001^{*}$ \\
\hline Inaccuracies & $1(7.14)$ & $2(15.38)$ & $0(0.00)$ & 0.070 \\
\hline
\end{tabular}

* Significant values $(\mathrm{p} \leq 0.05)$ - Fisher's exact test

Note: Group I = mild intermittent or mild asthma; Group II = moderate or severe persistent asthma; Group III = healthy children

showed that in all variables except "labial seal", differences were observed, with worse results in the experimental groups (Groups I and II) when they were compared to the control group (Group III).

Some authors ${ }^{(13)}$ underwent clinical assessment of chewing in children and adolescents with asthma and found no differences in the control group. Our findings were different from the results of the aforementioned study, demonstrating that there was a difference in chewing pattern of asthmatic children and healthy children.

There was predominance of changes in masticatory group of children with mild asthma when they were compared to a moderate or severe. Since we would expect exactly the opposite finding, further studies are needed to verify the relationship of asthma severity with changes in mastication. It should be noted that the presence of AR was statistically similar between the two groups.

\section{Swallowing versus asthma}

In the first evaluation of swallowing with cheese bread, it was observed that the "previous projection of language", "food stasis in the oral cavity", "periorbicular muscle contraction" and "contraction of the mentalis muscle" distinguished themselves by demonstrating differences between groups I and II compared to group III. These findings corroborate a previous study ${ }^{(14)}$, who highlighted the involvement of the perioral muscles, with anterior projection of the tongue, noisy swallowing and significant changes in resting posture of lips during the swallowing in patients with asthma.

Two variables, "moving head" and "interposition of the lower lip" had no difference. In the work mentioned above ${ }^{(14)}$ the same variables were described as part of swallowing process in patients with asthma.

The second evaluation of swallowing, using water, it was observed that the "projection of earlier language", "food stasis in the oral cavity", "muscle contraction periorbicular", "contraction of the mentalis muscle" and "lip interposition" showed differences between Groups I and II when they were compared to Group III. This result matched the data from previously cited work $^{(14)}$. Only the item "head movement" had no difference between groups.

Consistent with the results of chewing, swallowing also showed a higher percentage of changes in patients with lighter asthma. It should be noted that the presence of AR was statistically similar in the two groups.

\section{Speech versus asthma}

The literature adds little when it comes to the intersection between asthma and speech. In localized studies, speech is characterized as appropriate or modified without the mention of specific clinical assessment and specialized in their methods $^{(15-17)}$.

In Brazilian studies ${ }^{(15-17)}$ that aimed to characterize the prevalence, severity, and symptoms associated with asthma in children and adolescents, among other findings it was highlighted the presence of alterations in the speech of children 
with asthma. This alteration has been not been largely characterized. Thus, by describing changes in the speech of patients with asthma, the aforementioned studies and the present work have similarities. However, how the change was classified (by limiting wheeze), suggests that this report has only considered the inter-crisis period (asthma exacerbations), not having a permanent basis.

In contrast, in the present study the classification of speech as altered was not limited to crisis periods, assuming then the permanent character. We observed the presence of distortions in patients with mild asthma $(71.43 \%)$, with difference from the more severe asthmatic group and the group of healthy children.

The same phenomenon already described and discussed in the processes of chewing and swallowing was elucidated in the evaluation of speech. The increase in the level of asthma severity did not increase the occurrence of speech disorders. Therefore the group consisting of mild asthma had abnormal speech, with phonetic origin, characterized by the presence of distortion in the production of sounds. This fact was evidenced by the significant difference when comparing the speak profiles of this group with those of healthy children and patients with severe asthma.

\section{CONCLUSION}

From the findings of this study, we conclude that children with asthma have alterations in the process of chewing, swallowing and speech, regardless of the level of disease severity. The results suggest that asthma determines changes in oral functions regardless of the presence of allergic rhinitis.

\section{REFERENCES}

1. Marchesan IQ. Motricidade oral: visão clínica do trabalho fonoaudiológico integrado com outras especialidades. São Paulo: Pancast; 1993.

2. Carvalho GD. SOS respirador bucal: uma visão funcional e clínica da amamentação. São Paulo: Lovise; 2003.

3. Allergic Rhinitis and its Impact on Asthma. 2010 [cited 2012 May 17]. Available from: http://www.whiar.org/

4. IV Diretrizes Brasileiras para o Manejo da Asma. J Bras Pneumol. 2006;32(Supl 7):S447-74.
5. Fomin AB, Souza RG, Fiorenza RF, Castro AP, Pastorin AC, Jacob CM. Rinite perene: avaliação clínica e epidemiológica de 220 pacientes em ambulatório pediátrico especializado. Rev Bras Alergia Imunopatol. 2002;25(1):10-5.

6. Amaral CS, Martins ER, Amaral CS, Rios JB. A respiração bucal e o desenvolvimento do complexo dentofacial. Rev Bras Alergia Imunopatol. 2002;25(4):131-5.

7. Berger WE. Allergic rhinitis in children: diagnosis and management strategies. Paediatr Drugs. 2004;6(4):233-50.

8. Ciprandi G, Marseglia GL, Klersy C, Tosca MA. Relationship between allergic inflammation and nasal airflow in children with persistent allergic rhinitis due to mite sensitization. Allergy. 2005;60(7):957-60.

9. Branco A, Ferrari GF, Weber SA. Alterações orofaciais de doenças alérgicas de vias aéreas. Rev Paul Pediatr. 2007;25(3):266-70.

10. de Freitas FC, Bastos EP, Primo LS, de Freitas VL. Evaluation of the palate dimensions of patients with perennial allergic rhinitis. Int $\mathrm{J}$ Paediatr Dent. 2001;11(5):365-71.

11. de Lemos CM, Mello Júnior JF, Mion O. Alterações funcionais do sistema estomatognático em pacientes com rinite alérgica. Arq Int Otorrinolaringol. 2007;11(4):380-6.

12. Bernardes FF. Respiração bucal: o que os pais sabem a respeito. Rev CEFAC. 1999;1(2):18-24.

13. da Cunha DA, Lima RM, Nascimento GK, da Cunha RA, da Silva EG, da Silva HJ, et al. Antropometria e mastigação em crianças asmáticas. Rev CEFAC. 2009;11(Supl.3):341-8.

14. Bicalho GP, Motta AR, Vicente LC. Avaliação da deglutição em crianças respiradoras orais. Rev CEFAC. 2006;8(1):50-5.

15. Kuschnir FC, da Cunha AJ, Braga DA, da Silveira HH, Barroso MH, Aires ST. Asma em escolares de 13 e 14 anos do Município de Nova Iguaçu, Rio de Janeiro, Brasil: estimativas de prevalência, gravidade e diferenças de gênero. Cad Saúde Pública. 2007;23(4):919-26.

16. Breda D, Freitas PF, Pizzichini E, Agostinho FR, Pizzichini MM. Prevalência de sintomas de asma e fatores de risco associados em adolescentes escolares de 13 e 14 anos dos municípios de Tubarão e Capivari de Baixo, Santa Catarina, Brasil. Cad Saúde Pública. 2009;25(11):2497-506.

17. de Farias MR, Rosa AM, Hacon SS, Castro HA, Ignotti E. Prevalência de asma em escolares de Alta Floresta - município ao sudeste da Amazônia brasileira. Rev Bras Epidemiol. 2010;13(1):49-57.

18. Marchesan IQ. Protocolo de avaliação miofuncional orofacial. In: Krakauer L, Di Francesco R, Marchesan I, organizadores. Respiração oral. São José dos Campos: Pulso; 2003. p. 55-79. (Coleção CEFAC).

19. Saconato M, Guedes ZC. Estudo da mastigação e da deglutição em crianças e adolescentes com Sequência de Möbius. Rev Soc Bras Fonoaudiol. 2009;14(2):165-71.

20. Marchesan IQ. Práticas fonoaudiológicas: uma visão compreensiva [tese]. Campinas (SP): Universidade Estadual de Campinas; 1998. 